\title{
Increasing frequencies and changing characteristics of heavy precipitation events threatening infrastructure in Europe under climate change
}

\author{
Katrin M. Nissen and Uwe Ulbrich \\ Freie Universität Berlin, Institute of Meteorology, Carl-Heinrich-Becker-Weg 6-10, 12165 Berlin, Germany \\ Correspondence to: Katrin M. Nissen (katrin.nissen@met.fu-berlin.de)
}

Received: 20 October 2016 - Discussion started: 31 October 2016

Revised: 1 June 2017 - Accepted: 2 June 2017 - Published: 14 July 2017

\begin{abstract}
The effect of climate change on potentially infrastructure-damaging heavy precipitation events in $\mathrm{Eu}-$ rope is investigated in an ensemble of regional climate simulations conducted at a horizontal resolution of $12 \mathrm{~km}$. Based on legislation and stakeholder interviews the 10-year return period is used as a threshold for the detection of relevant events.

A novel technique for the identification of heavy precipitation events is introduced. It records not only event frequency but also event size, duration and severity (a measure taking duration, size and rain amount into account) as these parameters determine the potential consequences of the event. Over most of Europe the frequency of relevant heavy precipitation events is predicted to increase with increasing greenhouse gas concentrations. The number of daily and multi-day events increases at a lower rate than the number of sub-daily events. The event size is predicted to increase in the future over many European regions, especially for sub-daily events. Moreover, the most severe events were detected in the projection period. The predicted changes in frequency, size and intensity of events may increase the risk for infrastructure damages. The climate change simulations do not show changes in event duration.
\end{abstract}

\section{Introduction}

Parts of our infrastructure system are vulnerable to extreme weather. One of the risks threatening the European infrastructure network is heavy precipitation. A series of interviews conducted with infrastructure providers has revealed that land-based transportation infrastructure (i.e. streets and railway lines) is especially vulnerable to heavy precipitation (Groenemeijer et al., 2015) but the electricity network and the telecommunication network can also be affected if critical components (e.g. electrical substations) are flooded. In addition to the direct local effects such as short circuits and submergence, heavy precipitation can cause secondary hazards which in turn can also result in damages. The most frequent secondary hazards caused by precipitation are river floods, snow avalanches and landslides (Gill and Malamud, 2014).

In this paper we analyse the effect of climate change on potentially infrastructure-damaging heavy precipitation events in Europe. Estimating the risk that hazardous events pose to infrastructure is a complex task. In addition to hazard strength, it depends on exposure (the existence of an infrastructure element in the region affected by the hazard) and vulnerability (susceptibility of the infrastructure element to the hazard) (e.g. van Westen, 2013). These factors will however not be the subject of this study. Here we concentrate only on the hazard frequency and its characteristics, taking into account the size, duration and severity of the events.

Previous studies have already established that extreme precipitation is likely to increase with increasing greenhouse gas emissions. In their 2012 report on changes in climate extremes (Seneviratne et al., 2012) the Intergovernmental Panel on Climate Change (IPCC) states that it is likely that there have already been statistically significant increases in the number of heavy precipitation events in more regions of the world than there have been statistically significant decreases. The trends show, however, strong regional and sub-regional variations. In addition the report states that it is likely that the frequency of heavy precipitation or the proportion of to- 
tal rainfall from heavy rainfalls will increase in the 21st century over many areas of the globe. A pronounced change is expected for example in winter in the northern mid-latitudes.

Focusing on Europe, a review of trend analyses and climate change projections for extreme precipitation and floods was compiled by Madsen et al. (2014). The majority of studies cited in the review show an increase in extreme precipitation, with the definition of "extreme" varying between studies. A multi-model ensemble analysis of heavy precipitation under climate change conditions was conducted by Scoccimarro et al. (2016), who analysed a 20-member ensemble of coupled global model simulations which took part in phase 5 of the Coupled Model Intercomparison Project (CMIP5). The model ensemble predicts an increase in the intensity of heavy precipitation events over Europe for the Representative Concentration Pathway (RCP) 8.5 emission scenario in winter. During summer this increase is restricted to Northern Europe. Jacob et al. (2014) analysed a 10-member ensemble of regional EURO-CORDEX simulations and found that the 95th percentile of daily precipitation is predicted to increase by up to $35 \%$ in the RCP8.5 scenario until the end of the 21 st century.

With respect to the secondary hazards that can be triggered by heavy precipitation, a review compiled by Gariano and Guzzetti (2016) reports an increased risk for landslide fatalities in regions where climate change increases the frequency and intensity of severe precipitation. In contrast, the response of river floods to climate change is less homogeneous. According to a multi-model ensemble of climate change simulations the frequency of river floods will probably increase over Western Europe and decrease over most Eastern European regions (Hirabayashi et al., 2013). Especially catchments in which snowmelt dominates the peak flow are expected to see a decrease in flood magnitude (Madsen et al., 2014).

This study is the first that analyses projected changes in the characteristics of heavy precipitation events over Europe. We have developed a novel technique for the identification of such events that records event size, duration and severity in addition to event frequency. Size and severity are especially crucial parameters for stakeholders as they influence, for example, repair times and determine whether it is possible to compensate the failure (e.g. by using alternative routes). In addition, size, duration and severity determine whether an event is likely to trigger a secondary hazard. The probability for river floods, for instance, increases with increasing rain duration and affected catchment fraction, while event size is less important for landslides, which are often triggered by severe rain falling on already saturated soil (e.g. Kirschbaum et al., 2009).

The study was conducted using a high-resolution $\left(0.11^{\circ}\right)$ multi-model ensemble of regional simulations considering both multi-day and sub-daily events. A high spatial model resolution is important for reproducing the climatology of extreme daily and sub-daily precipitation over regions with substantial orography (Prein et al., 2016). Daily (or multiday) and sub-daily precipitation should be both considered because they cause different kinds of problems for infrastructure providers and can trigger different secondary hazards. Moreover, there is indication that they respond differently to increasing greenhouse gas emissions (e.g. Scoccimarro et al., 2015).

The work described in this paper was conducted within the EU-funded research project RAIN (Risk Analysis of Infrastructure Networks in response to extreme weather). The RAIN vision is to provide an operational analysis framework that identifies critical infrastructure components affected by extreme weather and that can be used to determine the most effective mitigation strategies. The implications of climate change on the hazards are one of the core components of the risk analysis framework.

The remainder of the paper is structured as follows. First the data sets analysed in this study are introduced. Section 3 describes how the thresholds for the detection of relevant events were determined. Next the newly developed method for the detection of extreme precipitation events is explained. Results for the present-day climate and the climate change signal are presented in Sects. 5 and 6 respectively. Conclusions are given in Sect. 7.

\section{Data}

A multi-model ensemble conducted within the EUROCORDEX framework (Jacob et al., 2014) is analysed. The EURO-CORDEX ensemble includes simulations by various regional climate models (RCMs) covering the European domain. The RCMs are driven by CMIP5 global climate model integrations. The data analysed for this study have a spatial resolution of $0.11^{\circ}(12 \mathrm{~km})$. We analysed 13 simulations for which data at a daily temporal resolution were available. Two RCM modelling groups have additionally provided data at 3-hourly temporal resolution for a total of seven simulations. The climate change signal is studied by comparing results of three different periods of simulated data for two different greenhouse gas scenarios. The reference is the "historical" period. It is produced using observed (1971-2000) greenhouse gas forcing and compared to the model simulations for the periods 2021-2050 and 2071-2100 forced with RCP8.5 and RCP4.5 representative greenhouse gas pathways (Moss et al., 2008). At the time of writing the number of available simulations for the more moderate RCP2.6 scenario was too low for robust results. This scenario is therefore not considered in the study. For the simulations forced by the Hadley Centre Global Environmental Model (HadGEM, Collins et al., 2008), data for year 2100 were not available. For these simulations we had to shift the analysed period 1 year back. The combinations of global and regional models used for this study are shown in Table 1. 
Table 1. EURO-CORDEX simulations analysed for this study and available temporal resolution of the data sets.

\begin{tabular}{llllll}
\hline GCM & RCA4 & RACMO22E & CCLM4-8-17 & HIRHAM5 & WRF331F \\
\hline EC-EARTH & day, 3h & day, 3h & day & day & \\
HadGEM2 & day, 3h & day, 3h & day & & \\
MPI-ESM & day, 3h & & day & & day \\
CM5A-MR & day, 3h & & day & & \\
CNRM-CM5 & day, 3h & & day & & \\
\hline
\end{tabular}

The ability of the EURO-CORDEX models to reproduce mean and extreme precipitation has been analysed by Prein et al. (2016) in a recent study. They compared the output of an ensemble of EURO-CORDEX simulations forced with ERA-Interim reanalysis data to several regional observational data sets and were able to show that the simulations at $0.11^{\circ}$ capture the observation more closely than the $0.44^{\circ}$ simulations with the largest improvement found for sub-daily rainfall over the Alps.

In our study simulated daily and multi-day rainfall accumulations are compared with observations using the gridded observational E-OBS data set (Haylock et al., 2008). The EOBS data set provides accumulated daily precipitation over land in Europe at a resolution of $0.25^{\circ}(28 \mathrm{~km})$. As no subdaily pan-European precipitation data set exists, modelled 3hourly rainfall was compared to downscaled ERA-Interim reanalysis data (i.e. the EURO-CORDEX "evaluation" simulations). A comparison to station data is shown for the example of the World Meteorological Organization (WMO) station Berlin using precipitation measurements at 1-hourly temporal resolution.

\section{Thresholds}

Within the RAIN project two surveys have been performed aiming to determine the thresholds at which failures of infrastructure elements may occur. Twenty-eight infrastructure providers from the fields of energy, telecommunication, land transport (streets and rail) and emergency rescue services were interviewed as well as 18 national and private weather services (Holzer et al., 2015). Not unexpectedly, there is no universal critical value for all types of infrastructure and all areas within Europe. For some providers the amount of precipitation falling within a day is more important for others it is the intensity per hour. The thresholds named by the stakeholders range between $5 \mathrm{~mm} \mathrm{~h}^{-1}$ (danger of aquaplane) and $30 \mathrm{~mm} \mathrm{~h}^{-1}$ for high-intensity events and between $50 \mathrm{~mm} \mathrm{day}^{-1}$ and $100 \mathrm{~mm} \mathrm{~h}^{-1}$ for events with high water accumulation.

It should be noted that the area mean values from gridded data sets, such as the ones analysed in this study, differ from the point values that affect an infrastructure element. Göber et al. (2008) for example show that the maximum precipitation value for daily rainfall at a point within a $40 \mathrm{~km} \times 40 \mathrm{~km}$ grid box can be more than twice as high as the grid-box mean value. Deviations increase with grid-box size and event severity. Thus, using the point value thresholds from the stakeholder interviews to detect heavy precipitation events in the gridded data sets would result in an underestimation of the number of identified events. We therefore decided not to use a fixed value threshold for the present study. Instead, this study will use local return values for a given return period as thresholds for extreme events (i.e. the amount of rain per time unit exceeded on average only every $n$ years). This approach is consistent with engineering practice and legislation (e.g. FGSV, 2005; Willems, 2013; UIC, 2008). Engineers who design drainage systems to protect infrastructure elements from (heavy) precipitation usually also determine the required capacity of the system from the local return levels at a given return period. In engineering terms these values are referred to as "design rainfall". The return periods that should be used are often specified by national laws and international recommendations. The International Union for Railways, for example, recommends using 10-year return periods (UIC, 2008) and German legislation prescribes return periods between 1 and 50 years for streets depending on the importance of the street (FGSV, 2005). Using these values seems reasonable as one can assume that only precipitation, which exceeds the design rainfall, can be harmful for the infrastructure component. The resulting thresholds are relative values which depend on the spatial resolution and on the climatology of the data set and will thus be calculated separately for each data set.

The return levels are estimated using a peak over threshold (POT) method, fitting a generalised Pareto distribution to events exceeding the local 95th percentile (only wet days are taken into account). This was done following Coles (2001) using the "extRemes" package of the statistical software package R. The return levels differ for events with different durations and different return periods. As illustrated in Fig. 1 for the example of the WMO station Berlin, the intensity of extreme precipitation events at a given return level typically increases with decreasing duration (Fig. 1a), while the accumulated amount increases with duration (Fig. 1b). The relationship between the intensity, the duration and the frequency of precipitation at a given place can be described with intensity-duration-frequency (IDF) curves and the relationship between accumulated rain amount (depth), dura- 
(a)

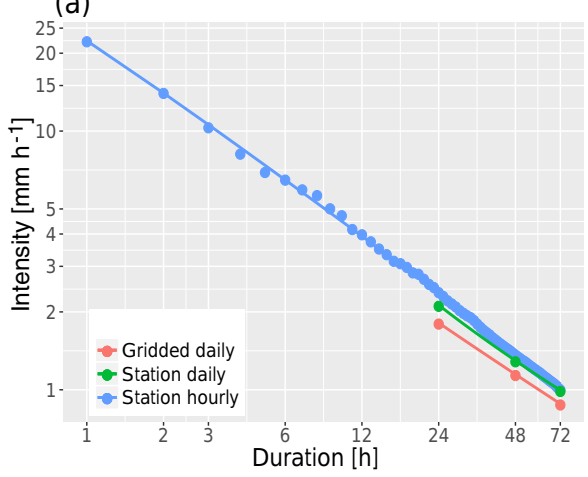

(b)

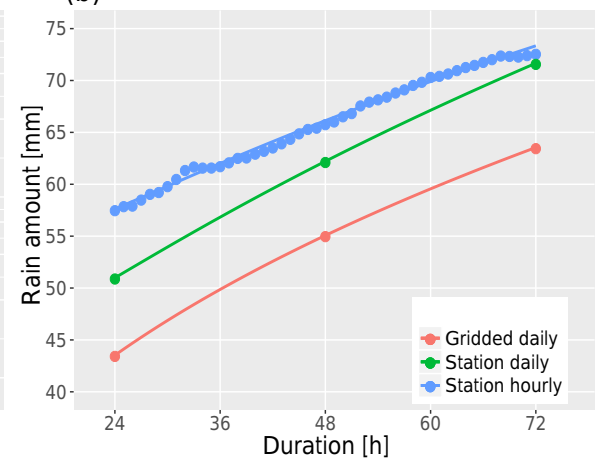

Figure 1. Dependence of (a) intensity in $\mathrm{mm} \mathrm{h}^{-1}$ and (b) accumulated rain amount (depth) in mm on rainfall duration. Blue: Berlin station data with hourly resolution; green: Berlin station data with daily resolution; red: closest grid point to Berlin from E-OBS data set at daily resolution. Dots indicate result of POT analysis, and solid lines are the fitted IDF and DDF curves (see text for details).

tion and frequency with depth-duration-frequency (DDF) curves. The mathematical expression which best describes the relationship between intensity (or depth) and duration varies between stations and depends on the precipitation type (convective, stratiform or mixed) dominating the duration classes (e.g. Malitz, 2005).

Empirical equations exist to model this relationship and to fit the curves (e.g. WMO, 2009). This approach leads to a smoother and more consistent relationship between the return values and the rainfall duration. In this study we have fitted the return values to

$i=\frac{a}{t^{c}+b}$,

where $i$ is intensity and $t$ is duration, while $a, b$ and $c$ are the fitting coefficients as in WMO (2009) Eq. (5.34). Depth can be obtained by multiplying $i$ with duration. The dots in Fig. 1 represent the output of the POT analysis and the solid lines show the IDF and DDF fits respectively. For Berlin (blue line) the 10 -year return value is $22.3 \mathrm{~mm}$ for hourly durations and $57.6 \mathrm{~mm}$ for daily durations. These values lie on the lower end of the range the infrastructure operators consider as relevant. We have therefore decided to use the present-day 10 -year return value as a threshold for the detection of potentially infrastructure threatening events.

How much the return values are affected by the temporal and spatial resolution of the data set is demonstrated by the green and red lines in Fig. 1. The effect of the temporal resolution can be seen by comparing the blue line (calculation from station data at hourly resolution) with the green line (calculated from station data at daily resolution). The difference is on the order of $10 \%$ and caused by the fact that the rainfall amount associated with a strong $24 \mathrm{~h}$ event will probably not all fall within the same data aggregation period but will contribute to the rain amount of two consecutive periods. Comparing the green and the red lines illustrates the effect of the spatial resolution. The green curve shows the IDF (DDF) curve for 10-year return values calculated from daily station data while the red line is the result of the same calculation from the grid box in the observational gridded E-OBS data set (Haylock et al., 2008), which includes the observational site. The gridding process again leads to a reduction of the return value by approx. $10 \%$. The exact differences depend on the orography and the grid resolution.

\section{Identification of extreme events}

A detection algorithm for precipitation extremes in a Lagrangian perspective was developed, which identifies events of various durations and spatial extents in gridded data sets. In a first step the algorithm identifies all grid boxes in which the rainfall exceeds a local threshold (here the 10-year return value). Exceedances caused by the same synoptic weather situation (e.g. passage of a front) are considered as belonging to the same event. In the algorithm this is realised by assigning all affected grid boxes embedded in the same area with considerable precipitation ( $>95$ th percentile) to the same event. This is schematically illustrated in Fig. 2. Areas with precipitation exceeding the threshold are shown in red in Fig. 2a. As all red areas are located within the same area of substantial rain, outlined by the green ellipse, they are considered as belonging to the same event and form a group. For each identified group an envelope surrounding the group is defined which contains the high-risk area. It is determined from the area where the smallest possible circle including all exceedance grid boxes (black outline in Fig. 2a) and the area where the 95th percentile is exceeded (green outline) overlap (hatched area). The events are then tracked in time. The group at time step $t+1$ is considered as the next track element which exhibits the largest overlap to the high-risk area from the previous time step (Fig. 2b).

To distinguish between long-duration events with high precipitation amounts and short-duration events with high rain intensities the algorithm is applied twice. First, daily to multi-day events are detected by searching for grid boxes 

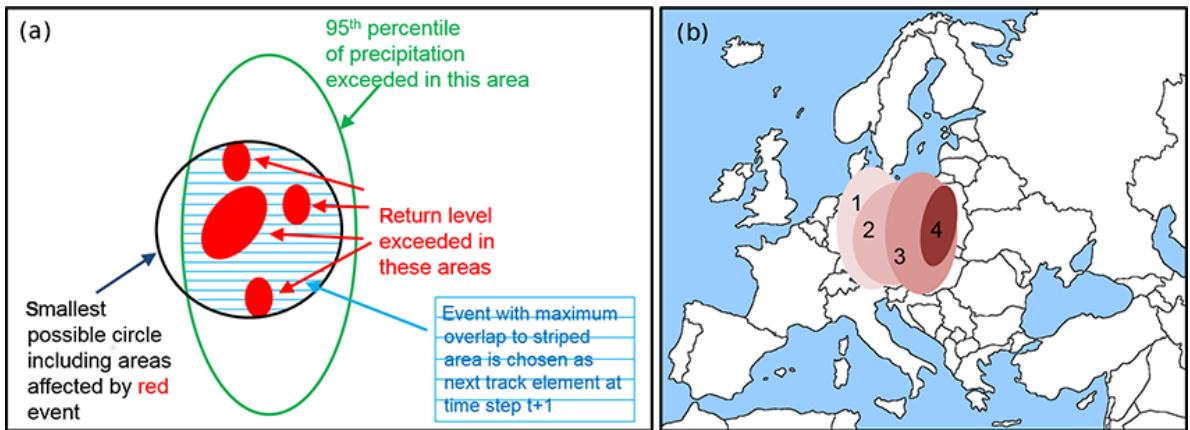

Figure 2. Schematic illustration of the detection and tracking scheme. (a) Grid boxes exceeding the detection threshold are grouped into events. (b) Events are tracked in time and space. See text for further explanation.

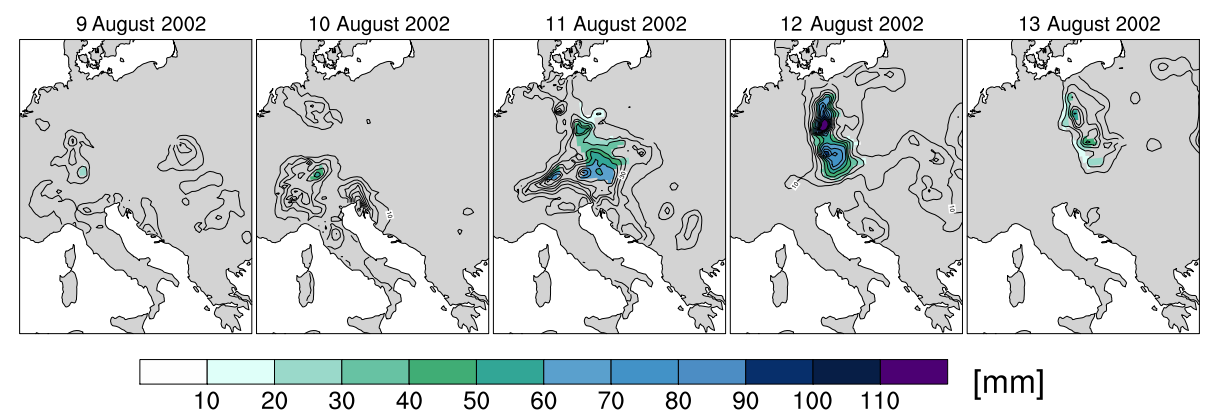

Figure 3. Precipitation for the period 9 to 13 August 2002 based on the E-OBS data set. Contour lines show daily precipitation amounts. Colour denotes grid boxes in which the local 10-year return levels are exceeded.

in which the 24,48 and/or $72 \mathrm{~h} 10$-year return value is exceeded. This is done for all 13 simulations. Secondly, subdaily events are detected by searching for grid boxes in which the 3-hourly 10-year return level is exceeded. This is done for the seven simulations for which data at such a temporal resolution were available.

Each detected event can consist of several grid boxes and can last for several time steps. A precipitation severity index (PSI) is defined which can be used to compare the strength of the identified events. It is calculated only from grid boxes and time steps where the 10-year return level was exceeded and is determined as follows:

PSI $=\sum_{t}^{T} \sum_{k}^{K} \frac{\operatorname{precip}_{k, t}}{\text { annualprecip }_{k}} \times A_{K}$,

where $T$ is the event duration, $K$ is the number of affected grid boxes and $A_{k}$ is the size of grid box $k$. Thus, the severity index takes the affected area and the amount of precipitation accumulated over the duration of the event into account. It is normalised by the long-term mean annual precipitation sum expected for the grid box.

An example for a detected event is shown for a historical case. In August 2002 record-breaking rainfall amounts and intensities occurred in Central Europe. They resulted in a large-scale flooding event (e.g. Ulbrich et al., 2003). Applied to the E-OBS data set, the detection algorithm identi- fies the event as depicted in Fig. 3. Displayed is the 5-day sequence between 9 and 13 August 2002. Shading denotes areas where the 10-year return levels were exceeded. These areas and time steps are attributed to the event, and thus the event duration determined by the algorithm is $185000 \mathrm{~km}^{2}$ and its duration 5 days. The severity index PSI for this event is 50, which corresponds to the 99th percentile of the PSI for all detected events within the E-OBS domain.

\section{Present-day climate}

\subsection{Daily and multi-day events}

Looking at the historical period (1971-2000), daily 10-year return values for the multi-model ensemble are highest over Iceland, western Norway, the Alps, north-western Spain and the Mediterranean coast (Fig. 4b). As expected the return values in the multi-model ensemble mean are generally higher than in the E-OBS data set (Fig. 4a) because of the higher horizontal resolution of the simulations. In addition, the models show a very pronounced north-south gradient with higher return values at more southerly latitudes, which is not present in the E-OBS observations. In the Mediterranean the inter-model standard deviation (SD) is also high, indicating a large spread between the model simulations in this region (Fig. 4c). It is not possible to decide whether the differences 

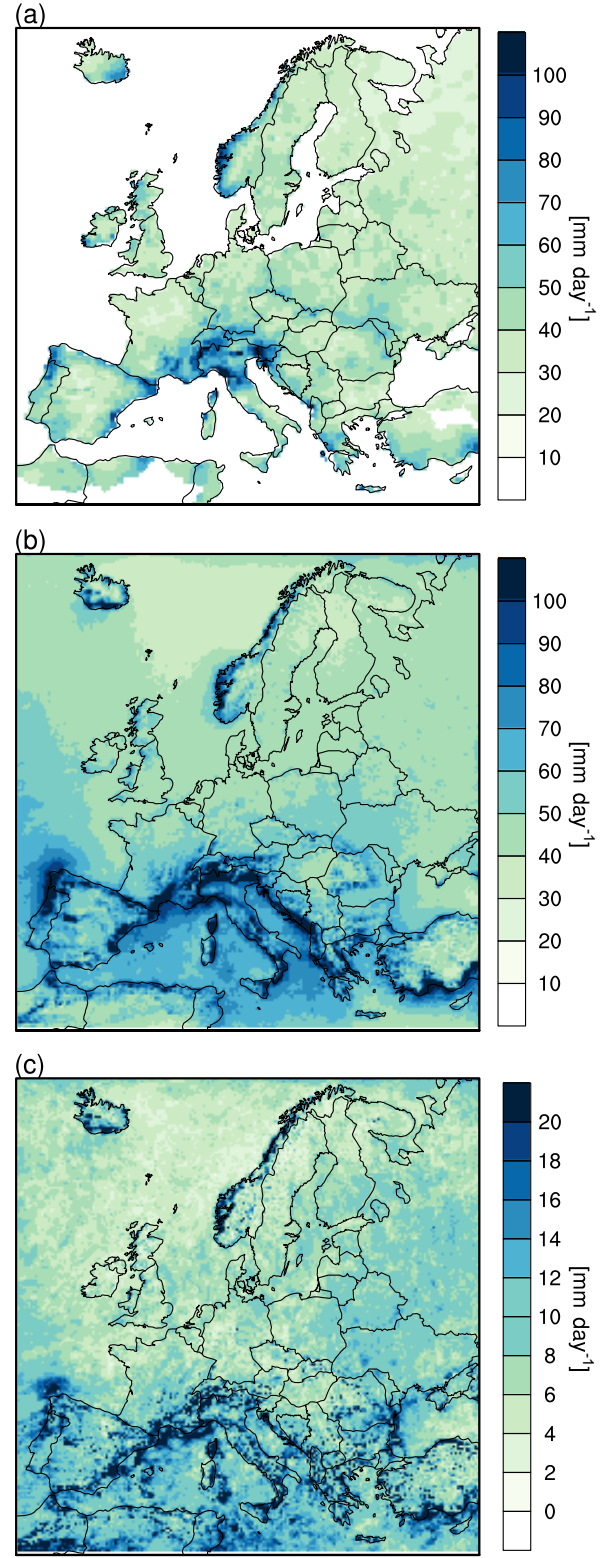

Figure 4. 10-year return level of daily precipitation in the E-OBS data set and the EURO-CORDEX simulations for the period 19712000. (a) E-OBS data set (b) ensemble mean of EURO CORDEX simulations (c) ensemble SD.

between the model simulations and the observations can be regarded as model deficits as Prein and Gobiet (2016) have shown that the magnitude of the uncertainty associated with the E-OBS data set is of the same order as the uncertainty associated with regional climate model simulations even on a seasonal scale.

The 48 and $72 \mathrm{~h}$ return levels exhibit a very similar spatial distribution to the $24 \mathrm{~h}$ return values with somewhat higher accumulated amounts and the maximum values in some grid
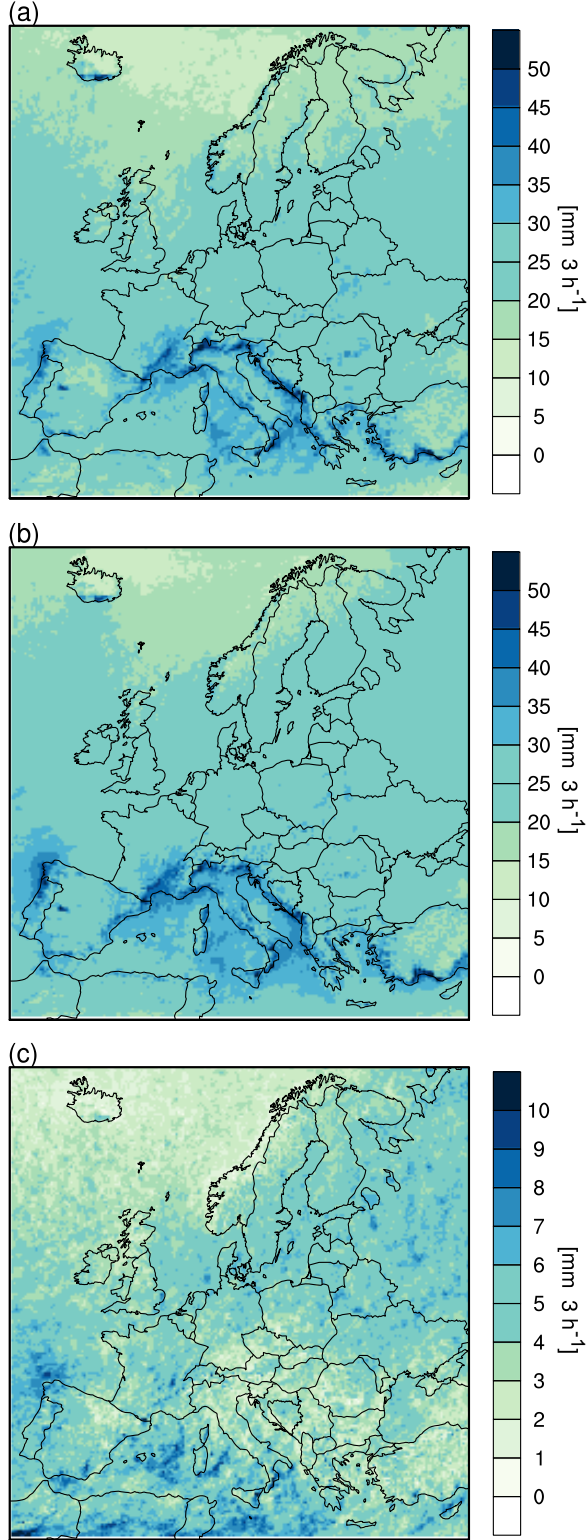

Figure 5. 10-year return level of 3-hourly precipitation. (a) ERAInterim downscaled with RCA4 and RACMO22E for the period 1981-2010 (b) ensemble mean of EURO CORDEX simulations (c) ensemble SD.

boxes exceeding $300 \mathrm{~mm}$ in $48 \mathrm{~h}$ and $400 \mathrm{~mm}$ in $72 \mathrm{~h}$ respectively (not shown, but available from Nissen, 2016).

\subsection{Sub-daily events}

As there is no gridded pan-European observational data set at 3-hourly resolution available, Fig. 5a shows 10-year return levels calculated from precipitation data obtained by downscaling the ERA-Interim reanalysis (Dee et al., 2011) with the two regional EURO-CORDEX models for which 3-hourly data were stored (ensemble mean of RCA4 and 
RACMO22E). The period shown on the upper panel is 19812010 instead of the reference period 1971-2000 that is shown on the lower panels as ERA-Interim only starts in 1979. The high similarity in the return levels in panels Fig. 5a and b suggests that the precipitation distribution might be strongly influenced by the regional models and should be regarded with caution. The 3-hourly 10-year return values for the multimodel ensemble reach values up to $50 \mathrm{~mm}$ in $3 \mathrm{~h}$. The highest values can be found over the Alps, at the Mediterranean coast, southern Iceland and north-western Spain (Fig. 5b). The inter-model SD is highest over the southern Mediterranean, the north-west of Spain and north-eastern Europe (Fig. 5c). Results in these regions may not be robust enough for interpretation.

\section{Climate change signal}

The climate change signal in the multi-model ensemble is studied by comparing frequency, size, severity and duration of heavy precipitation events between the simulated historical period (1971-2000) and the two scenario periods (20212050 and 2071-2100). First, the differences in the number of detected events were calculated at each grid point. The result was tested both for statistical significance and for consistency between the model simulations. This was done in two steps. In the first step, the significance in each model was tested independently using the following bootstrap technique: the detected events were randomly redistributed between the two periods (historical and scenario) and the difference between the two periods was determined. This process was repeated 1000 times. If the observed difference between the two periods exceeded the randomly obtained difference in $90 \%$ of the cases, the change is significant at the $90 \%$ level. According to IPCC recommendations (Mastrandrea et al., 2010) a hypothesis can be considered as "very likely" at a statistical significance level of $90 \%$. The test was applied to neighbouring groups of nine grid boxes and the result was assigned to the central box. Including neighbouring boxes increases the sample size, rewards regions which show a consistent signal and punishes inhomogeneous areas. The second step of the testing process is meant to ensure consistency between the model simulations. Only those grid boxes at which $90 \%$ of the simulations show a statistically significant signal of the same sign pass the test. Grid boxes passing both tests are marked by black dots in Figs. 6 and 9. The test is much stricter than the one applied by Jacob et al. (2014), where only $66 \%$ of the models had to agree on the direction of the change.

\subsection{Changes in daily and multi-day events}

The climate change simulations suggest that the frequency at which an individual grid box is hit by a long-duration heavy precipitation event increases with increasing greenhouse gas concentrations over most European regions (Fig. 6). The highest increases can be found on the westward-facing sides of the European coasts, for example over western Scandinavia, western Ireland, western Scotland and the western Balkans. By the end of the century and under RCP8.5 conditions infrastructure elements in these regions may be affected by potentially damaging long-lasting precipitation events more than twice as often as under present-day climate conditions (i.e. every $4-5$ years instead of once every 10 years). In Central Europe the frequency may increase to once every 5-7 years (up to $100 \%$ ) at some grid boxes. The lowest increase, and for some grid boxes even a decrease, is simulated for the western Mediterranean region. For the first half of the century the simulations predict a modest increase for both emission scenarios over most of Europe, mostly staying below 1 event in 20 years (probability change of $50 \%$ ). For this period only few grid boxes pass the strict two-step test for statistical significance and consistency. The climate signal increases steadily over time and with increasing emissions, suggesting a robust relationship between greenhouse gas concentrations and the frequency of heavy precipitation events. This is reflected in the size of the area where the signal is statistically significant, which also increases with time and emission levels.

When counting the detected extreme precipitation events there is a clear dependence of the number of events and of the detected changes on the season. The annual cycle of the events for the sub-regions marked in Fig. 6 is depicted in Fig. 7, both for the historical period (1971-2000) and for the scenario period 2071-2100. It illustrates that in the Mediterranean area most extreme precipitation events occur during autumn. In Western, Central and Northern Europe, however, it is more likely to experience such an event during summer.

By the end of the century the annual mean change in the number of events in the pessimistic RCP8.5 scenario amounts to $49 \%$ for the British Isles, $99 \%$ for Scandinavia and $73 \%$ for Central Europe. Over the Iberian Peninsula the overall change is negative $(-6 \%)$. Here the climate change simulations suggest a slight increase in the number of heavy precipitation events for some winter months, while the number of events during the other seasons decreases. Over Scandinavia, the British Isles and Central Europe the number of detected events increases under climate change conditions during all seasons. Over Britain and Ireland the summer maximum may start to extend well into autumn. For this region, the highest increase in terms of absolute numbers is found for autumn and the lowest for spring. The annual cycle of the climate change signal for the British Isles suggests that an increase of the sea surface temperatures in the North Atlantic may be one aspect leading to the increase in the number of heavy precipitation events in this region. The ocean remains comparably warm well into the winter season leading to enhanced evaporation. This in turn increases the water supply available for precipitation. The effect decreases when the ocean is at its coldest at the end of the winter season. 

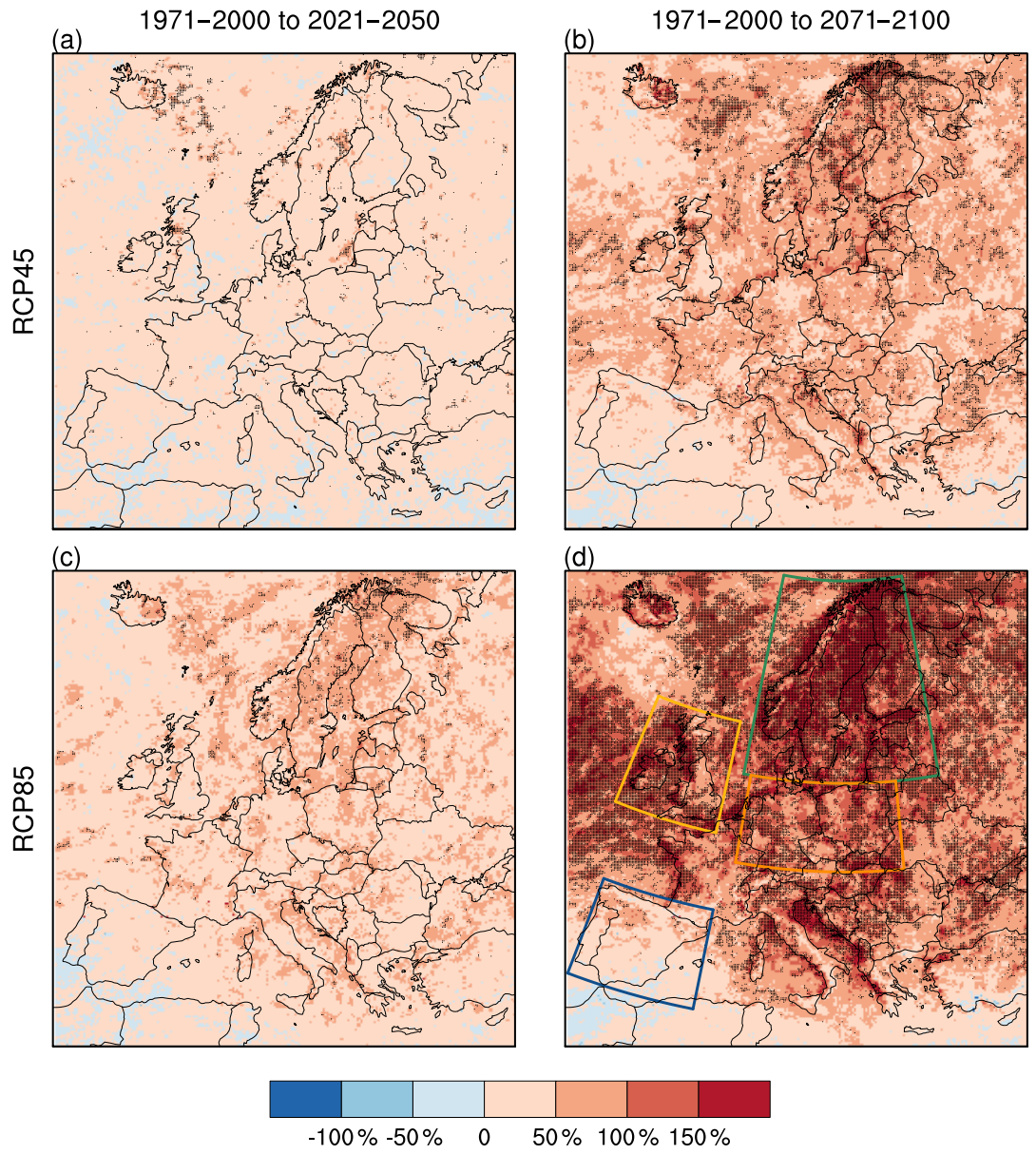

Figure 6. Relative change of probability of events with 10-year return period between the historical simulations (1971-2000) and the scenario simulations (a 2021-2050 for RCP4.5 scenario, b 2071-2100 for RCP4.5 scenario, c 2021-2050 for RCP8.5 scenario, d 2071-2100 for RCP8.5 scenario). Ensemble mean for daily and multi-day events. Dots denote statistical significance and inter-model consistency. Areas marked in panel (d) are selected for further analysis.

Central Europe shows an increase for the number of events for all seasons, which in terms of percentage change is highest during winter. This may be caused by an increase in winter temperatures under climate change conditions. The highest and temporally most homogeneous percentage increase can be found for Scandinavia. For the RCP8.5 scenario the number of events almost doubles until the end of the century in all seasons. For the more moderate RCP4.5 scenario the changes expected until the end of the century amount to approximately $60 \%$ of the changes predicted for the RCP8.5 scenario. An exception is the Iberian Peninsula, which shows a non-homogeneous behaviour between the scenarios for some months consistent with the lack of statistical significance and inter-model consensus evident in Fig. 6.

The increases in event counts due to increasing greenhouse gas levels shown in Fig. 7 appear in some regions more moderate than the frequency increases found for some individual grid boxes (Fig. 6). This is due to the fact that the frequency at which a grid box is hit depends on the number of events in the area and on their size as a larger event affects more grid boxes. Thus, for Fig. 7 each event is only counted once regardless of its size, while it is counted for each grid box it affects in Fig. 6. For an individual infrastructure element the analysis on grid-box basis shown in Fig. 7 would be more relevant as larger events increase the risk for the element to be affected. The size of the larger $50 \%$ of events is predicted to slightly increase in all analysed regions except for Scandinavia (Fig. 8). In terms of severity, the strongest events occur in the climate change simulations, even though the median of the PSI remains unchanged or even decreases. No pronounced changes in event duration could be detected anywhere within Europe (not shown).

\subsection{Changes for sub-daily events}

The increase in occurrence probability under climate change conditions at single grid boxes reaches values that are approximately 2 times larger for sub-daily events (Fig. 9) than 


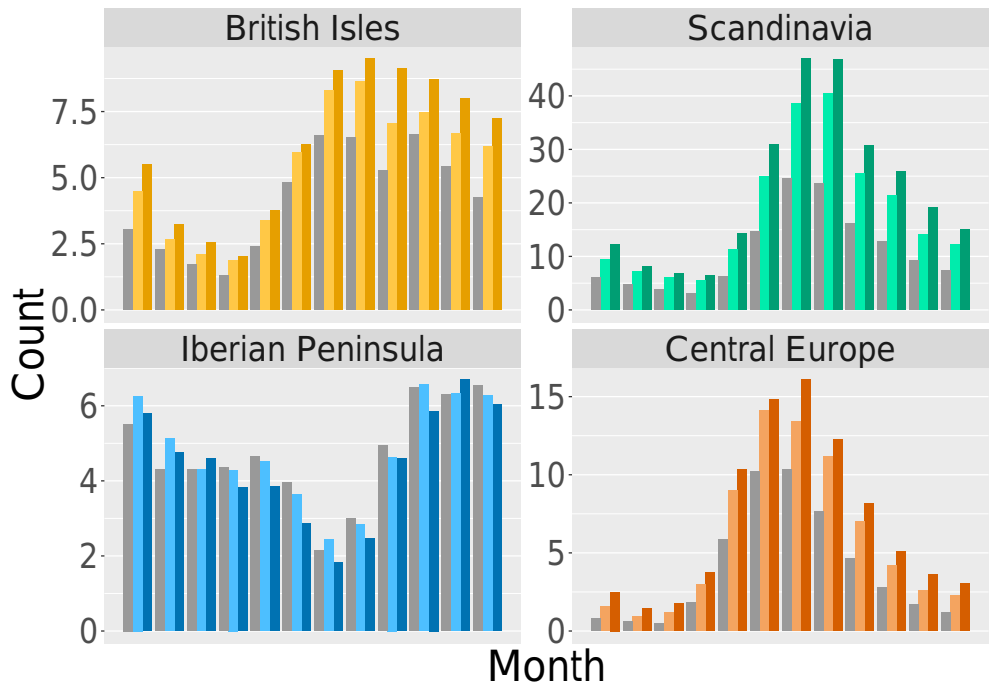

Figure 7. Seasonal cycle of detected daily and multi-day heavy precipitation events in four different European regions (British Isles, Iberian Peninsula, Scandinavia and Central Europe). The ensemble mean for the historical simulation (grey), the RCP4.5 (light colour) and the RCP8.5 (bright colour) scenario simulation for the period 2071-2100 are shown.
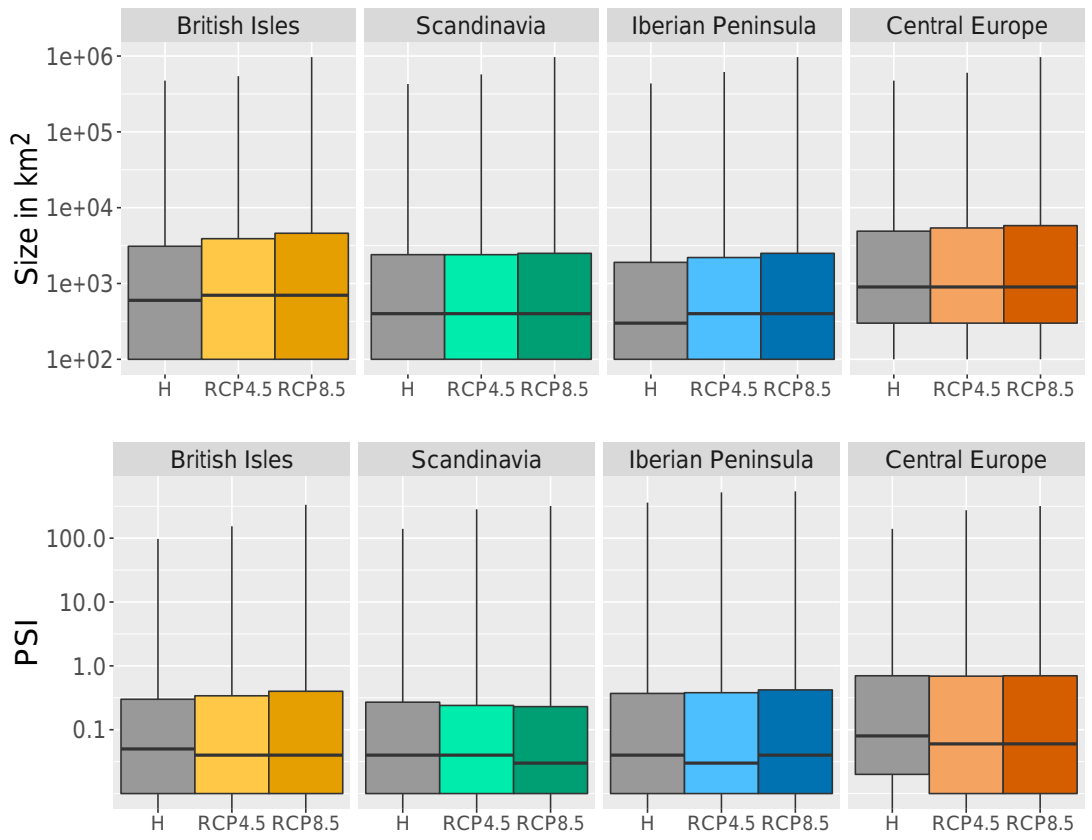

Figure 8. Size and strength distribution of detected daily and multi-day heavy precipitation events in four different European regions (British Isles, Iberian Peninsula, Scandinavia and Central Europe). The ensemble mean for the historical simulation (grey), the RCP4.5 (light colour) and the RCP8.5 (bright colour) scenario simulation for the period 2071-2100 are shown. The box plots show the median, 25th and 75th percentile and the whiskers span the range from the smallest to the largest event.

for long-lasting events (Fig. 6), making it necessary to use different colour scales for the figures. The increases become stronger and more significant with increasing greenhouse gas concentrations. The regions showing the highest increase in high-intensity events at the end of the 21 st century are similar to those detected for long-lasting events: Scandinavia and the western coasts of the British Isles as well as Iceland. Here, the occurrence probability for sub-daily precipitation event in the RCP8.5 scenario increases in some grid boxes from once every 10 years by more than $300 \%$ to once every $2-3$ years. Even the western Mediterranean region shows a pronounced increase for sub-daily events which is similar in magnitude to 

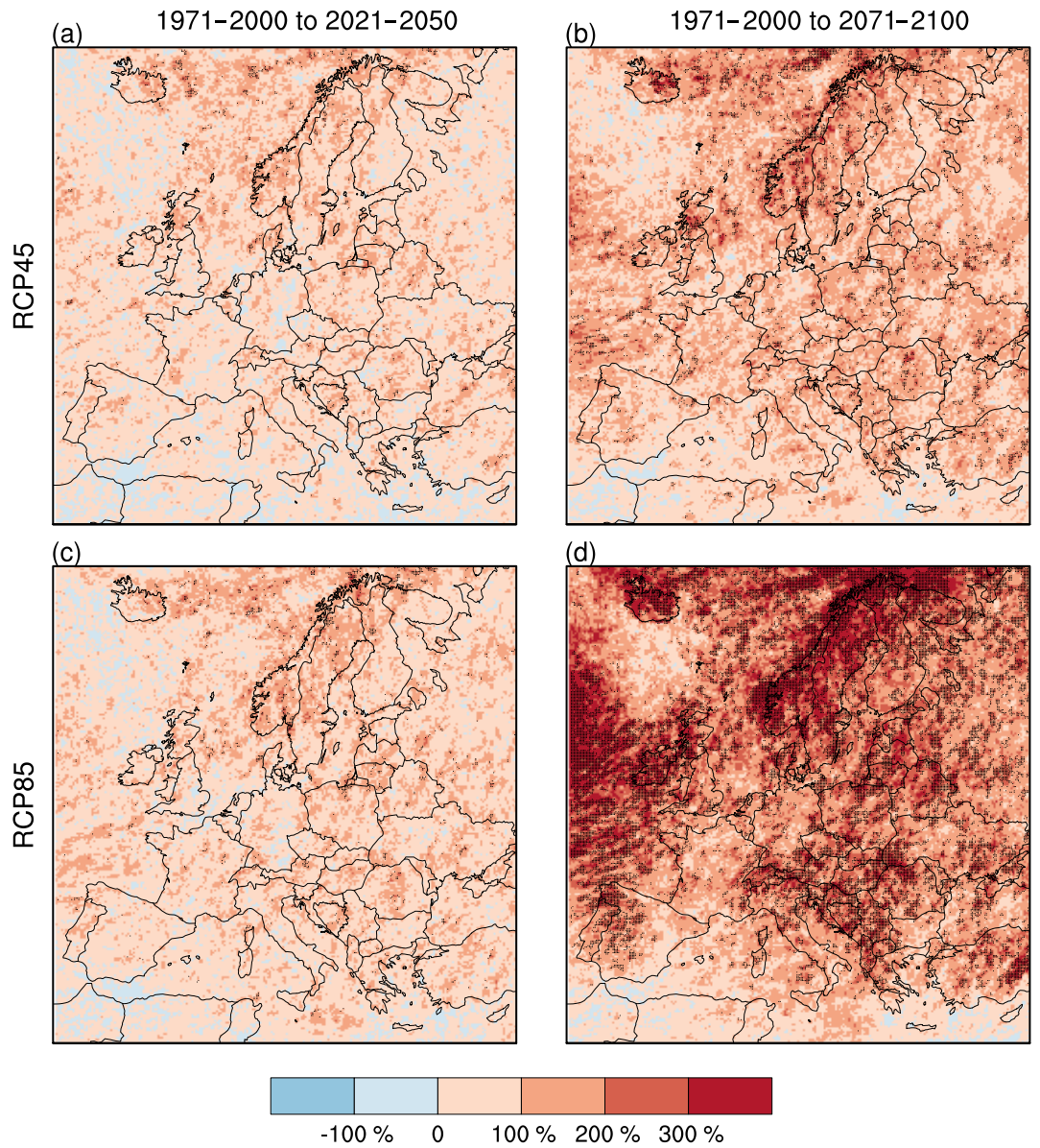

Figure 9. Relative change of probability of events with 10-year return period between the historical simulations (1971-2000) and the scenario simulations (a 2021-2050 for RCP4.5 scenario, b 2071-2100 for RCP4.5 scenario, c 2021-2050 for RCP8.5 scenario, d 2071-2100 for RCP8.5 scenario). Ensemble mean for sub-daily events. Dots denote statistical significance and inter-model consistency.

the increase simulated for France and Germany (up to $100 \%$ in some grid boxes).

Again, the increases in event counts per region (Fig. 10) are more moderate than the increases in the frequency at which individual grid boxes are affected (Fig. 9). The annual increase of the number of sub-daily events averaged over the region of the British Isles is $51 \%$, for Scandinavia $107 \%$, for Central Europe $56 \%$ and for the Iberian Peninsula $16 \%$ for the RCP8.5 scenario. The difference in the strength of the increases between event numbers and frequency at the grid-box scale can be attributed to the fact that the events are predicted to increase in size (Fig. 11).

The seasonal cycle of sub-daily event occurrence is similar to the one found for daily and multi-day events (Fig. 10): over the British Isles, Central Europe and Scandinavia heavy precipitation events mostly occur during summer, while the most active season in the western Mediterranean region is autumn. In terms of percentage the highest increases in the number of sub-daily heavy precipitation events can be found during autumn and winter (Iberian Peninsula, British Isles,
Central Europe) or spring (Scandinavia). The simulations suggest that Central Europe will start to see high-intensity precipitation events during winter, which were almost nonexistent during the historical period of the climate simulations (Fig. 10) and in the downscaled ERA-Interim simulations (not shown). This result is probably caused by higher winter temperatures in the scenario simulations. During summer the increase in the number of sub-daily heavy precipitation events is less pronounced in most regions. The western Mediterranean even sees a decrease in the number of events during this season. With a more moderate greenhouse gas increase under the RCP4.5 scenario the simulated changes until the end of the century are almost as strong $(75 \%)$ as the changes predicted for the pessimistic RCP8.5 scenario.

Sub-daily events are in general smaller and weaker (in terms of PSI) than daily and multi-day events (Figs. 8 and 11). Sub-daily events tend to be stronger over the Iberian Peninsula and Central Europe than over Scandinavia and the British Isles. The strongest events of the time series for all regions except Scandinavia are detected for the scenario pe- 


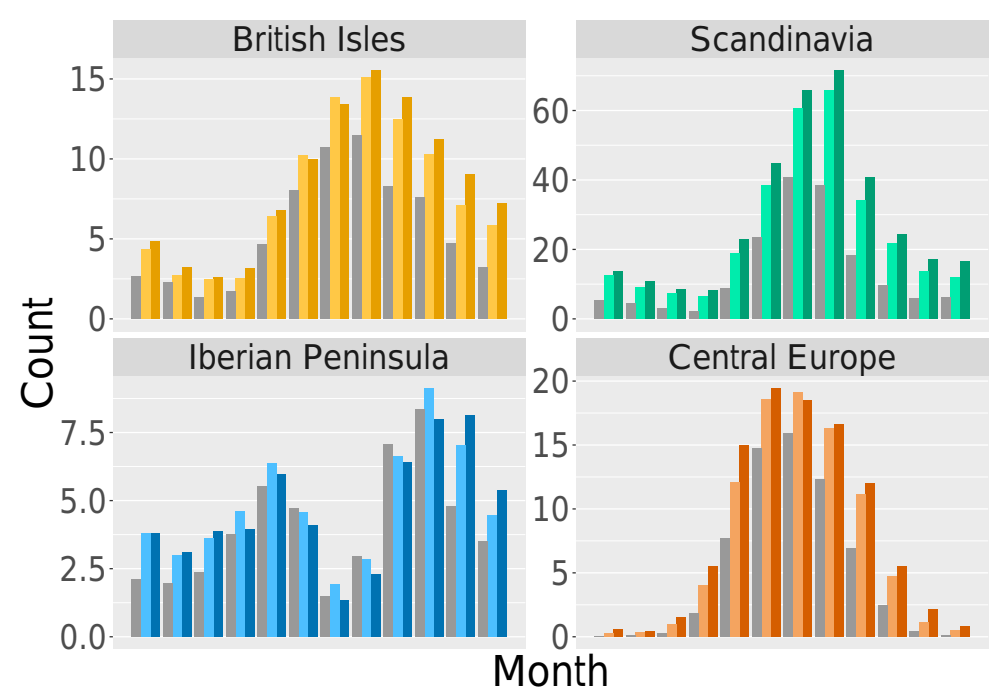

Figure 10. Seasonal cycle of detected sub-daily heavy precipitation events in four different European regions (British Isles, Iberian Peninsula, Scandinavia and Central Europe). The ensemble mean for the historical simulation (grey), the RCP4.5 (light colour) and the RCP8.5 (bright colour) scenario simulation for the period 2071-2100 are shown.

riods, although the median of the PSI remains stable. Again, no change was found for the event duration (not shown).

\section{Discussion}

The overall increase for projected extreme precipitation found in this study is supported by other scientific publications. There is a consensus that an increase in air temperatures, which is associated with increasing greenhouse gas concentrations, will probably lead to an increase in extreme precipitation. The IPCC report states that proportionately more precipitation is expected per precipitation event over most regions for future climate periods (Seneviratne et al., 2012). This can be explained by the fact that with increasing surface temperatures, the moisture-holding capacity of the atmosphere increases. When sufficient moisture is available, precipitation extremes are expected to increase by $6-7 \%$ per degree $\mathrm{K}$ according to the Clausius-Clapeyron (CC) relation.

For daily and multi-day event frequencies at the gridbox scale the spatial distribution of the changes is in good agreement with Jacob et al. (2014), who analysed a similar multi-model ensemble but using a lower threshold (95th percentile). Our results also agree with many studies in the literature which compare temperature dependent changes of daily and sub-daily extremes (e.g. Westra et al., 2014, and references therein). With respect to Europe, Lenderink and van Meijgaard (2008), for example, show for a regional model simulation and a Dutch station that already under presentday conditions extreme hourly precipitation increases with temperature at a much higher rate than extreme daily precipitation, even exceeding the $\mathrm{CC}$ relation. A similar analysis by Molnar et al. (2015) investigating $10 \mathrm{~min}$ intensities for Swiss stations also shows super CC scaling for convective events. A different conclusion is reached by Scoccimarro et al. (2015), who analysed changes in the 90th percentile of wet days for sub-daily and daily precipitation in winter using a coupled atmosphere-ocean RCM. In their study the model predicts the highest percentage changes over most of Europe for daily events. The result may, however, be influenced by the choice of the threshold used. According to Ban et al. (2015), comparing percentiles of wet days between two periods may not correctly represent changes in extremes if the number of dry time steps differs between the two periods. Another factor of uncertainty is the choice of the convection scheme used in the RCM as this can have a strong influence on simulated heavy precipitation (Cavicchia et al., 2016).

To eliminate the uncertainties associated with convection parameterisation some pioneering studies have been performed in which convection-permitting regional climate change simulations are analysed. For southern Britain convection-resolving simulations studied by Kendon et al. (2014) predicted stronger increases for high sub-daily precipitation percentiles (wet days only) than for high daily percentiles with scaling at a super CC rate. Ban et al. (2015), in contrast, found that the intensities of both hourly and daily extreme precipitation scale with temperature at the CC rate in a $2.2 \mathrm{~km}$ resolution RCM simulation over the Alps. Comparing a $7 \mathrm{~km}$ convection-parameterising model with a convection-permitting $2.8 \mathrm{~km}$ resolution RCM in southern Germany, Fosser et al. (2016) found similar climate change signals for both models. If only wet days are considered the scaling reaches super $\mathrm{CC}$ rates for hourly precipitation in the convection-permitting model. If all days are taken into account the CC relationship holds. 

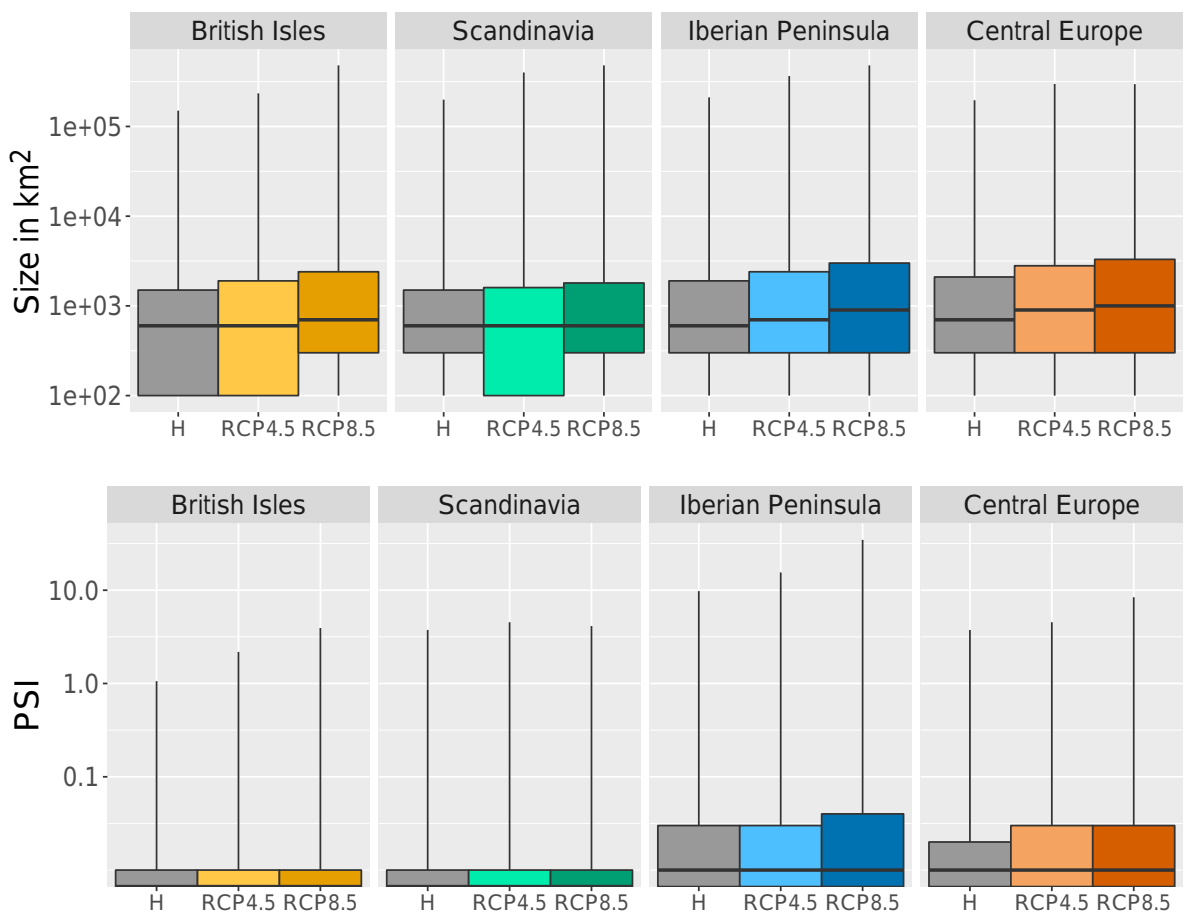

Figure 11. Size and strength distribution of detected sub-daily heavy precipitation events in four different European regions (British Isles, Iberian Peninsula, Scandinavia and Central Europe). The ensemble mean for the historical simulation (grey), the RCP4.5 (light colour) and the RCP8.5 (bright colour) scenario simulation for the period 2071-2100 are shown. The box plots show the median, 25th and 75th percentile and the whiskers span the range from the smallest to the largest event.

This discussion shows that it is important to analyse subdaily and daily events as it is not possible to extrapolate subdaily changes from daily data. As studying the evolution of extreme events has been put increasingly into the focus of climate change studies, it would be desirable to routinely store sub-daily data when conducting CMIP simulations.

\section{Conclusions}

In this study we analysed projected changes in the characteristics of heavy precipitation events over Europe. A novel technique was developed and applied, which identifies and tracks heavy precipitation events. It allows us to evaluate not only event frequency but also event size, duration and severity.

According to an ensemble of regional climate model simulations from the EURO-CORDEX initiative forced with increasing greenhouse gas concentrations, the probability of infrastructure failures due to heavy precipitation will increase in the future. When planning new infrastructure, drainage systems should be installed that allow for higher discharges than currently observed. This study shows that all over Europe the highest increases can be expected for sub-daily events with high intensities. At some grid boxes the increases are predicted to increase by $300 \%$ until the end of the 21 st century under the pessimistic RCP8.5 scenario. However, also under the more moderate RCP4.5 scenario the increases are substantial and can reach up to $75 \%$ of the changes simulated for RCP8.5.

The number of daily and multi-day events with high rain amounts is also predicted to increase in the future for most European regions, however, at a slightly lesser rate (up to $150 \%$ ). An exception is the western Mediterranean region where the number of daily and multi-day events is predicted to decrease.

The climate change simulations also suggest that the areas affected by heavy precipitation events may become larger in many European regions especially for sub-daily events. This can have consequences for infrastructure networks. Largerscale events may damage more infrastructure elements at the same time. It becomes more difficult to compensate for damages by using neighbouring elements and more personnel may be needed for repairs and emergency services. In addition, the probability that the event can lead to a river flood increases. The median in event strength remains stable or even decreases in all analysed areas. Nevertheless, the strongest events within the time series are always detected in the scenario periods. This suggests that infrastructure providers may have to cope with unprecedented events in the future. 
Data availability. The simulations analysed for this study are available from the Earth System Grid Federation (ESGF) data server. The ensemble-mean distribution of present-day 10-year return levels as well as event frequency for different scenario periods and event durations is stored in a public repository (Nissen, 2016).

Competing interests. The authors declare that they have no conflict of interest.

Acknowledgements. The work described in this paper was conducted within the EU-funded research project RAIN (Risk Analysis of Infrastructure Networks in response to extreme weather). The RAIN research project is a Seventh Framework Program under contract no. 608166. Uwe Ulbrich's research has been partially funded by Deutsche Forschungsgemeinschaft (DFG) through grant CRC1114 "Scaling Cascades in Complex Systems", project A01.

We acknowledge the E-OBS data set from the EU-FP6 project ENSEMBLES (http://ensembles-eu.metoffice.com) and the data providers in the ECA\&D project (http://www.ecad.eu). We would like to thank the two anonymous reviewers for their constructive comments, which helped to improve the manuscript. Our special thanks go to Erik van Meijgaard and Grigory Nikulin for providing the high-temporal-resolution precipitation data.

Edited by: Paolo Tarolli

Reviewed by: two anonymous referees

\section{References}

Ban, N., Schmidli, J., and Schär, C.: Heavy precipitation in a changing climate: does short-term summer precipitation increase faster?, Geophys. Res. Lett., 42, 1165-1172, 2015.

Cavicchia, L., Scoccimarro, E., Gualdi, S., Marson, P., Ahrens, B., Berthou, S., Conte, D., Dell'Aquila, A., Drobinski, P., Djurdjevic, V., Dubois, C., Gallardo, C., Li, L., Oddo, P., Sanna, A., and Torma, C.: Mediterranean extreme precipitation: a multi-model assessment, Clim. Dynam., https://doi.org/10.1007/s00382-0163245-x, online first, 2016.

Coles, S.: An Introduction to Modeling of Extreme Values, Springer, London, UK, 2001.

Collins, W. J., Bellouin, N., Doutriaux-Boucher, M., Gedney, N., Hinton, T., Jones, C. D., Liddicoat, S., Martin, G., O’Connor, F., Rae, J., Senior, C., Totterdell, I., Woodward, S., Reichler, T., and Kim, J.: Evaluation of the HadGEM2 model, Met Office Hadley Centre Technical Note HCTN 74, Met Office, FitzRoy Road, Exeter EX1 3PB, available at: https://digital.nmla.metoffice.gov.uk/ archive/ (last access: 11 July 2017), 2008.

Dee, D. P., Uppala, S. M., Simmons, A. J., Berrisford, P., Poli, P., Kobayashi, S., Andrae, U., Balmaseda, M. A., Balsamo, G., Bauer, P., Bechtold, P., Beljaars, A. C. M., van de Berg, L., Bidlot, J., Bormann, N., Delsol, C., Dragani, R., Fuentes, M., Geer, A. J., Haimberger, L., Healy, S. B., Hersbach, H., Hólm, E. V., Isaksen, L., Kållberg, P., Köhler, M., Matricardi, M., McNally, A. P., Monge-Sanz, B. M., Morcrette, J.-J., Park, B.K., Peubey, C., de Rosnay, P., Tavolato, C., Thépaut, J.-N., and Vitart, F.: The ERA-interim reanalysis: configuration and perfor- mance of the data assimilation system, Q. J. Roy. Meteor. Soc., 137, 553-597, https://doi.org/10.1002/qj.828, 2011.

FGSV: Teil: Entwässerung (RAS-Ew), Forschungsgesellschaft für Straßen- und Verkehrswesen, Richtlinie für die Anlage von Straßen, Köln, Germany, 2005.

Fosser, G., Khodayar, S., and Berg, P.: Climate change in the next 30 years: what can a convection-permitting model tell us that we did not already know?, Clim. Dynam., 48, 1987-2003, https://doi.org/10.1007/s00382-016-3186-4, 2016.

Gariano, S. L. and Guzzetti, F.: Landslides in a changing climate, Earth Sci. Rev., 162, 227-252, https://doi.org/10.1016/j.earscirev.2016.08.011, 2016.

Gill, J. C. and Malamud, B. D.: Reviewing and visualizing the interactions of natural hazards, Rev. Geophys., 52, 680-722, https://doi.org/10.1002/2013RG000445, 2014.

Göber, M., Zsótér, E., and Richardson, D. S.: Could a perfect model ever satisfy a naïve forecaster? On grid box mean versus point verification, Meteorol. Appl., 15, 359-365, 2008.

Groenemeijer, P., Becker, N., Djidara, M., Gavin, K., Hellenberg, T., Holzer, A. M., Juga, I., Jokinen, P., Jylhä, K., Lehtonen, I., Mäkelä, H., Morales Napoles, O., Nissen, K. M., Paprotny, D., Prak, P., Púčik, T., Tijssen, L., and Vajda, A.: Past cases of extreme weather impact on critical infrastructure in Europe, project report, available at: http://rain-project.eu/wp-content/uploads/ 2015/11/D2.2-Past-Cases-final.compressed.pdf (last access: 11 July 2017), 2015.

Haylock, M. R., Hofstra, N., Klein Tank, A. M. G., Klok, E. J., Jones, P. D., and New, M.: A European daily highresolution gridded data set of surface temperature and precipitation for 1950-2006, J. Geophys. Res., 113, D20119, https://doi.org/10.1029/2008JD010201, 2008.

Hirabayashi, Y., Mahendran, R., Koirala, S., Konoshima, L., Yamazaki, D., Watanabe, S., Kim, H., and Kanae, S.: Global flood risk under climate change, Nat. Clim. Change, 3, 816-821, https://doi.org/10.1038/nclimate1911, 2013.

Holzer, A. M., Becker, N., van Gelder, P. H. A. J. M., Gregow, H., Groenemeijer, P., Juga, I., Morales Napoles, O., Nissen, K. M., Nurmi, P., Paprotny, D., Púčik, T., Ulbrich, U., Vajda, A., and Venäläinen, A.: Present state of risk monitoring and warning systems in Europe, project report, available at: http://rain-project.eu/wp-content/uploads/2015/11/D2. 3-Warning-Systems.pdf (last access: 11 July 2017), 2015.

Jacob, D., Petersen, J., Eggert, B., Alias, A., Christensen, O. B., Bouwer, L., Braun, A., Colette, A., Déqué, M., Georgievski, G., Georgopoulou, E., Gobiet, A., Menut, L., Nikulin, G., Haensler, A., Hempelmann, N., Jones, C., Keuler, K., Kovats, S., Kröner, N., Kotlarski, S., Kriegsmann, A., Martin, E., Meijgaard, E., Moseley, C., Pfeifer, S., Preuschmann, S., Radermacher, C., Radtke, K., Rechid, D., Rounsevell, M., P. Samuelsson, P., Somot, S., Soussana, J. F., Teichmann, C., Valentini, R., Vautard, R., Weber, B., and Yiou, P.: EURO-CORDEX: new high-resolution climate change projections for European impact research, Reg. Environ. Change, 14, 563-578, https://doi.org/10.1007/s10113-013-0499-2, 2014.

Kendon, E. J., Roberts, N. M., Fowler, H. J., Roberts, M. J., Chan, S. C., and Senior, C. A.: Heavier summer downpours with climate change revealed by weather forecast resolution model, Nature Climate Change, 4, 570-576, https://doi.org/10.1038/nclimate2258, 2014. 
Kirschbaum, D. B., Adler, R., Hong, Y., and Lerner-Lam, A.: Evaluation of a preliminary satellite-based landslide hazard algorithm using global landslide inventories, Nat. Hazards Earth Syst. Sci., 9, 673-686, https://doi.org/10.5194/nhess-9-673-2009, 2009.

Lenderink, G. and van Meijgaard, E.: Increase in hourly precipitation extremes beyond expectations from temperature changes, Nat. Geosci., 1, 511-514, https://doi.org/10.1038/ngeo262, 2008.

Madsen, H., Lawrence, D., Lang, M., Martinkova, M., and Kjeldsen, T.: Review of trend analysis and climate change projections of extreme precipitation and floods in Europe, J. Hydrol., 519, 3634-3650, https://doi.org/10.1016/j.jhydrol.2014.11.003, 2014.

Malitz, G.: KOSTRA-DWD-2000 Starkniederschlagshöhen für Deutschland (1951-2000), Grundlagenbericht, available at: https://www.dwd.de/DE/fachnutzer/wasserwirtschaft/ kooperationen/kostra/grundlagenbericht_pdf.pdf?_blob= publicationFile\&v=3 (last access: 11 July 2017), 2005.

Mastrandrea, M. D., Field, C. B., Stocker, T. F., Edenhofer, O., Ebi, K. L., Frame, D. J., Held, H., Kriegler, E., Mach, K. J., Matschoss, P. R., Plattner, G.-K., Yohe, G. W., and Zwiers, F. W.: Guidance Note for Lead Authors of the IPCC Fifth Assessment Report on Consistent Treatment of Uncertainties, available at: http://www.ipcc.ch (last access: 11 July 2017), 2010.

Molnar, P., Fatichi, S., Gaál, L., Szolgay, J., and Burlando, P.: Storm type effects on super Clausius-Clapeyron scaling of intense rainstorm properties with air temperature, Hydrol. Earth Syst. Sci., 19, 1753-1766, https://doi.org/10.5194/hess-19-17532015, 2015.

Moss, R., Babiker, M., Brinkman, S., Calvo, E., Carter, T., Edmonds, J., Elgizouli, I., Emori, S., Erda, L., Hibbard, K., Jones, R., Kainuma, M., Kelleher, J., Lamarque, J. F., Manning, M., Matthews, B., Meehl, J., Meyer, L., Mitchell, J., Nakicenovic, N., O’Neill, B., Pichs, R., Riahi, K., Rose, S., Runci, P., Stouffer, R., van Vuuren, D., Weyant, J., Wilbanks, T., van Ypersele, J. P., and Zurek, M.: Towards New Scenarios for Analysis of Emissions, Climate Change, Impacts, and Response Strategies, Intergovernmental Panel on Climate Change, p. 132, available at: http://www.ipcc.ch/pdf/supporting-material/ expert-meeting-report-scenarios.pdf (last access: 11 July 2017), 2008.

Nissen, K. M.: Pan-European gridded data sets of heavy precipitation probability of occurrence under present and future climate, Freie Universität Berlin, Dataset, https://doi.org/10.4121/uuid:63c786a4-5ea4-471d-9d90c2e0c71006a9, 2016.

Prein, A. F. and Gobiet, A.: Impacts of uncertainties in European gridded precipitation observations on regional climate analysis, Int. J. Climatol., 37, 305-327, https://doi.org/10.1002/joc.4706, 2016.
Prein, A. F., Gobiet, A., Truhetz, H., Keuler, K., Goergen, K., Teichmann, C., Fox Maule, C., van Meijgaard, E., Déqué, M., Nikulin, G., Vautard, R., Colette, A., Kjellström, E., and Jacob, D.: Precipitation in the EURO-CORDEX $0.11^{\circ}$ and $0.44^{\circ}$ simulations: high resolution, high benefits?, Clim. Dynam., 46, 383-412, https://doi.org/10.1007/s00382-015-2589-y, 2016.

Scoccimarro, E., Villarini, G., Vichi, M., Zampieri, M., Fogli, P. G., Bellucci, A., and Gualdi, S.: Projected changes in intense precipitation over Europe at the daily and subdaily time scales, J. Climate, 28, 6193-6203, https://doi.org/10.1175/JCLID-14-00779.1, 2015.

Scoccimarro, E., Gualdi, S., Bellucci, A., Zampieri, M., and Navarra, A.: Heavy precipitation events over the EuroMediterranean region in a warmer climate: results from CMIP5 models, Reg. Environ. Change, 16, 595-602, https://doi.org/10.1007/s10113-014-0712-y, 2016.

Seneviratne, S. I., Nicholls, N., Easterling, D., Goodess, C. M., Kanae, S., Kossin, J., Luo, Y., Marengo, J., McInnes, K., Rahimi, M., Reichstein, M., Sorteberg, A., Vera, C., and Zhan, X.: Changes in climate extremes and their impacts on the natural physical environment, Chap. 3, 109-230, Cambridge University Press, Cambridge, UK, and New York, NY, USA, 2012.

UIC: Earthworks and Track Bed for Railway Lines, Union Internationales des Chemins der Fer, 3 Edn., Paris, France, 2008.

Ulbrich, U., Brücher, T., Fink, A. H., Leckebusch, G. C., Krüger, A., and Pinto, J. C.: The Central European flood of August 2002: Part 1 - Rainfall periods and flood development, Weather, 58, 371-377, https://doi.org/10.1256/wea.61.03A, 2003.

van Westen, C. J.: Remote sensing and GIS for natural hazards assessment and disaster risk management, in: Treatise on Geomorphology, 259-298, Academic Press, San Diego, CAP, 2013.

Westra, S., Fowler, H. J., Evans, J. P., Alexander, L. V., Berg, P., Johnson, F., Kendon, E. J., Lenderink, G., and Roberts, N. M.: Future changes to the intensity and frequency of short-duration extreme rainfall, Rev. Geophys., 52, 522-555, https://doi.org/10.1002/2014RG000464, 2014.

Willems, P.: Revision of urban drainage design rules after assessment of climate change impacts on precipitation extremes at Uccle, Belgium, J. Hydrol., 496, 166-177, https://doi.org/10.1016/j.jhydrol.2013.05.037, 2013.

WMO: The Guide to Hydrological Practices. II Management of Water Resources and Application of Hydrological Practices, available at: http://www.whycos.org/hwrp/guide/index.php (last access: 11 July 2017), 2009. 